\title{
RESSIGNIFICAR OS VÍNCULOS PARA PROMOVER NOVOS MODOS DE COEXISTIR
}

\author{
Lazslo Antonio Ávila \\ Faculdade de Medicina de São José do Rio Preto, São José do Rio Preto-SP, Brasil
}

\begin{abstract}
RESUMO
O mundo vive um tempo de mudanças catastróficas. Um tempo de mortes, violência, pobreza, degradação ambiental, exploração econômica e genocídio. As mais diversas esferas da vida demonstram que muito antes e além da pandemia o mundo já exigia transformações sociais profundas. Utilizaremos aqui dados estatísticos sobre a Educação e sobre a violência vivida pelos povos originários, os afrodescendentes e outros grupos marginalizados para propor o enfrentamento dessa situação. As concepções originais de líderes indígenas brasileiros apontam um caminho possível.
\end{abstract}

Palavras-chave: Psicanálise; vínculos; violência; genocídio.

\section{RESIGNIFYING BONDS TO PROMOTE NEW WAYS TO COEXIST}

\begin{abstract}
The world is in a time of catastrophic change. It is a time of death, violence, poverty, environmental degradation, economic exploitation, and genocide. Long before and beyond the pandemic, the diverse spheres of life demonstrate that the world already demanded profound social transformations. Here, we will use statistical data on Education and violence experienced by native peoples, Afro-descendants, and other marginalized groups, to propose how to confront this situation. The original conceptions of Brazilian indigenous leaders point to a possible path.
\end{abstract}

Keywords: Psychoanalysis; bonds; violence; genocide.

\section{ENLANCES RESIGNIFICADOS PARA PROMOVER NUEVAS FORMAS DE CONVIVIR}

\section{RESUMEN}

El mundo se encuentra en una época de cambios catastróficos. Una época de muerte, violencia, pobreza, degradación ambiental, explotación económica y genocidio. Los más diversos ámbitos de la vida demuestran que mucho antes y más allá de la pandemia, el mundo ya exigía profundas transformaciones sociales. Aquí, utilizaremos datos estadísticos sobre Educación y sobre la violencia vivida por los pueblos originarios, afrodescendientes y otros grupos marginados, para proponer cómo enfrentar esta situación. Las concepciones originales de los líderes indígenas brasileños apuntan a un camino posible.

Palabras clave: Psicoanálisis; vínculos; violencia; genocidio. 
O presente artigo é o texto original apresentado em forma de conferência no XV Encontro Luso-Brasileiro de Grupanálise e Psicoterapia Analítica de Grupo, XIII Congresso Brasileiro de Psicanálise das Configurações Vinculares, XX Congresso Nacional da SPGPAG e XIV Jornada da SPAGESP, realizado em formato on-line, em 23 de outubro de 2021. Vamos buscar pensar as profundas transformações que estamos vivendo nessa época que, como tem sido apontado por diversos filósofos, é mais do que uma era de mudanças, é uma mudança de Eras. Atravessamos um momento de inflexão na história humana e talvez na própria história da vida nesse planeta onde coexistimos.

O tema muito adequado desse Congresso de Psicanálise de Grupos é a Ressignificação. O que quer dizer "ressignificar"? Fundamentalmente, ressignificar é redefinir, recompor, requalificar, reenquadrar, ampliar os sentidos, produzir novos modos de pensar, sentir e agir.

Esta apresentação está dividida em duas partes. Primeiro vou discutir o impacto da pandemia sobre a sociedade em geral, porém centrando a análise sobre as consequências que acometeram os habitantes dos grandes centros urbanos. Depois vou enfocar a questão da crise, muito mais ampla e urgente, que afeta ao planeta como um todo, e que diz respeito ao modo como a civilização humana se conduziu até agora.

\section{O IMPACTO EMOCIONAL DA PANDEMIA NA CONVIVÊNCIA HUMANA}

Quem poderia imaginar as transformações globais que um simples vírus poderia causar em plena era de domínio técnico e desenvolvimento socioeconômico acelerado, como o que o mundo vivia até 2020? Quantas transformações na vida cotidiana, nos hábitos e nas atitudes, nos padrões de vida das populações, na saúde e na educação, na economia de cada país, nas relações entre as nações, no geral e no particular, em todo o mundo. Mudanças que afetaram o modo como cada um de nós pensava o seu próprio viver, o presente e o futuro, o pessoal e o coletivo.

Houve, logo no início da expansão acelerada do contágio, um grafite muito interessante pintado em uma estação do metrô de Tóquio com o seguinte dizer: "Quando vamos voltar ao normal? Qual normal? Nunca foi normal."

Ao ler esse grafite, imediatamente me lembrei de outro grafite muito emblemático, esse escrito em um muro de Paris, durante o levante estudantil-operário de 1968. Contrapondo-se ao muito conhecido ditado que diz que a liberdade de cada um vai até onde começa a do outro, esse grafite anônimo dizia: "A sua liberdade amplia a minha até o infinito."

Nessa forma tão contemporânea de se expressar, esses dois grafites, separados por mais de 50 anos, traduzem a perplexidade atual, e o forte desejo de mudança, de transformação, de renovação e de superação que existem latentes na população que habita os grandes centros urbanos e que vive mais agudamente os paradoxos que agitam o homem contemporâneo.

Vamos nos deter um pouco em cada um desses escritos, tentando decifrar o mundo presente em que vivemos ou sobrevivemos. Depois, vamos nos concentrar no que podemos esperar de um mundo pós-pandêmico, com algumas breves indicações de onde ainda se pode esperar extrair perspectivas para um mundo melhor. É nesse momento que poderemos colocar o Grupo como fulcro para ações possíveis.

Quando vamos voltar ao normal? O dito normal era péssimo, terrível, esmagador. $\mathrm{O}$ homem contemporâneo é um homem fundamentalmente assustado, 
desorientado, perplexo e angustiado frente a um mundo cujos mecanismos e fundamentos ele não entende, um mundo que o domina e o submete. Um mundo cheio de ameaças visíveis e invisíveis. Um mundo instável, imprevisível. Um mundo cheio de produtos, lotado de promessas, mas que ou ele não pode alcançar esses produtos maravilhosos por falta de recursos, ou quando os alcança, descobre, infeliz, que os produtos de consumo não lhe trazem mais bem-estar e felicidade. $\mathrm{O}$ homem atual trabalha demais, desgasta-se demais, se exige demais, é um homem abatido e deprimido. Parece que as inegáveis conquistas civilizatórias se voltaram contra ele. $\mathrm{O}$ progresso técnico não o tornou mais pleno, mas exigiu sempre mais dele. A sua longevidade aumentou, enormemente, mas não lhe deu sentido de vida, não o abasteceu de satisfação em viver, ou em significados a transmitir. Vive-se hoje em sociedades mais ricas, mas mais pobres em valores, mais carentes de significado e de transcendência.

O que era normal e vigente no ano de 2019? Trabalhar demais, viver para consumir, apavorar-se com a violência urbana, estressar-se com o trânsito, com os impostos, com a política, com a polícia, com os vizinhos. Normal era sentir medo, sentir raiva, sentir impotência frente às injustiças que se via por toda parte. Era normal sentirse deslocado, inquieto, irritado, alienado. Que normal é esse? E, olhando o mundo mais amplo, será que era normal a miséria que afeta um terço da população mundial? Normal o racismo? Normal o extermínio de populações, entre elas os indígenas brasileiros? Normais as migrações e as expulsões de migrantes? Normal a fome mundial que afeta mais de 800 milhões de pessoas?

Não, podia ser comum e parecer inevitável, mas normal não era. Nunca foi moralmente aceitável um mundo assim injusto. Não podemos considerar normal ainda haver tanta disparidade de renda, de saúde, de acesso aos bens culturais. Para ficarmos no domínio da Educação, e apenas concentrados na realidade de nosso próprio país, vamos citar alguns números:

Quantos analfabetos ainda existem no Brasil?: 11 milhões de pessoas, acima dos 15 anos, 6,6 \% da população, segundo o PNAD - Pesquisa Nacional por amostra de domicílio, IBGE (2019).

Quantos estudantes que entram no ensino fundamental o completam? Apenas 55 $\%$ dos que ingressam no primeiro ano do ciclo.

Quantos atingem o Ciclo Médio de ensino? Apenas 63,5 \%, dois milhões do total de 3,2 milhões de brasileiros com até19 anos.

Quantos chegam até à Universidade? Somente 27,2\% dos jovens entre 18 e 24 anos ingressam em uma faculdade. Quantos se tornam mestres? Quantos doutores formamos? Respectivamente, $0,5 \%$ e $0,1 \%$ da população brasileira de 25 a 65 anos.

Um estudo recente, publicado no jornal $O$ Globo, de 12 de outubro de 2021, levantou quanto tempo levaria para um professor da rede pública brasileira atingir o nível salarial dos super-salários que alguns privilegiados do próprio setor público recebem - o resultado é que demorariam 10.941 anos. Precisa alguma outra estatística?

A conclusão inevitável é a de que, se a Educação for o principal fator para nos levar para fora do subdesenvolvimento, teremos que ajudar a promover uma imensa transformação nas regras, procedimentos, estruturas e principalmente no financiamento da Educação em todo o país. E isso só pode ocorrer se paralelamente estiver acontecendo uma grande modificação nas regras, procedimentos e estruturas dos demais setores do Estado brasileiro, em relação a todo o conjunto das políticas públicas. 
Assim, o "normal" poderia se aproximar o mínimo do que é desejável e do que é o almejável para a construção de um país mais justo, mais decente e mais desenvolvido.

É preciso, e é mesmo fundamental, uma transformação política que trabalhe profundamente o fosso social entre os muito ricos (menos de $1 \%$ da população brasileira) e os muito pobres. Nunca poderia merecer o rótulo de "normal" uma realidade onde apenas $1 \%$ fica com mais de $50 \%$ da riqueza nacional (UOL, 2021). Será preciso criar mecanismos de taxação dos super-ricos, de mudança das estruturas que promovem essa concentração obscena de riqueza.

Isso nos leva ao segundo grafite. O que é a liberdade? Qual a liberdade que necessitamos? É liberdade aceitar passivamente essa realidade opressora? É a liberdade que dá o direito para os super-ricos continuarem a acumular riquezas e a produzir pobrezas? É livre quem pode escolher entre ficar desempregado ou ganhar um baixíssimo salário? É livre quem é analfabeto? É livre quem nasce de uma etnia que não é a dominante em seu país? É livre quem não pode decidir os rumos da política de seu país, embora possa votar? O que é o voto, quando não se pode controlar o comportamento dos eleitos? Qual liberdade existe se não se pode de fato escolher?

Mas, talvez, a liberdade de todos possa ampliar a de cada um. Talvez ser livre seja poder escolher buscar a própria liberdade, compreendendo que ela não pode ser individual, a minha liberdade se comunica necessariamente com a liberdade alheia.

Talvez possamos compreender e agir de fato buscando a ampliação simultânea de todos, a liberdade de pensar um novo modo de existir, uma nova política, uma nova vivência coletiva.

Qual foi o impacto socioemocional da pandemia do COVID-19 sobre o mundo? Ela piorou quase tudo. Mais fome, mais miséria, maior distância entre pobres e ricos, entre nações desenvolvidas e subdesenvolvidas. Mais depressão, mais suicídios. Mais solidão, mais feminicídios, mais abusos domésticos, mais violência. Devastação do meio ambiente e sem precedente na Amazônia. Medo e pânico disseminados. Polarização política que levou a rupturas, e a uma paralisia geral na capacidade de diálogo e de busca pelo bem comum.

Parece que aumentaram também as iniciativas de solidariedade, de compartilhamento, de auxílio mútuo e de algumas instituições agindo de modo mais eficaz no enfrentamento da fome e do desamparo, aqui no Brasil e mundo afora. Houve, com certeza, um aumento da consciência mundial - a consciência de que a sorte dos outros importa, e muito. Uma lenta e crescente compreensão de que, como humanidade, levamos muito longe o individualismo, a busca de ganho, a busca de lucro, a busca de domínio, a busca de poder. O egoísmo individual levado ao extremo, o nacionalismo exacerbado e o capitalismo selvagem aproximaram-se perigosamente da borda do abismo. Há um espanto coletivo e uma lenta aproximação de uma verdade dolorosa, mas transformadora: o mundo é aquilo que fizermos dele - e até agora fizemos muito, mas o melhor ficou para muito poucos.

Há um profundo desejo por um mundo melhor, e a Educação tem um papel central. Precisamos também de saúde, decerto. Porém o que mais precisamos é de sociedades mais bem organizadas, mais fraternas, mais solidárias, mais responsáveis por toda a sua população. Como construir uma sociedade melhor? Formando cidadãos melhores.

O que é realmente importante educar? Saber cálculo e gramática, ou aprender a ser solidário? Aprender Geografia, ou aprender convivência? Aprender História, ou aprender com a História? 
Passemos, agora, ao segundo ponto. Dissemos, de início, que a tarefa de ressignificar era urgente.

É tarefa urgentíssima. O mundo está à beira de um grande abismo: abismo ecológico e humanitário. Estamos diante de uma voragem que pode nos engolir a todos. Biomas estão desaparecendo; formas de vida se extinguem, espécies diversas desaparecem a cada dia; enormes contingentes humanos padecem fome, miséria e violências; etnias, com suas línguas, costumes e tradições, desaparecem acelerada e continuamente.

Há mortes por toda a parte. É um apocalipse anunciado. Deve ser enfrentado, precisamos mudar o rumo da marcha da Civilização, repensar e redefinir o papel que a Humanidade tem no mundo, tanto para si mesma, quanto frente a todo o conjunto de formas animadas e inanimadas de nosso comum ambiente. São as mudanças do Antropoceno, a era geológica em que o ser humano é o principal fator de transformação.

É tarefa urgentíssima, mas gigantesca, extremamente complexa, multiforme, entranhada, emaranhada, presa nos meandros de nossa história. Porque compõem nossos hábitos, nossas formas de pensar, nossos meios habituais de enfrentar os problemas da vida, ressignificar vai envolver aceitarmos processos mutativos em nossas subjetividades, em nossas relações grupais, institucionais e sociais.

Já não podemos mais pensar em situações ou fatos isolados, descontextualizados. Hoje não é apenas o mundo que está globalizado. Começamos a compreender que tudo está envolvido em tudo, que o local age e sofre a influência do geral. Não há mais como desvincular o particular do universal. Como os mais antigos místicos, tal como Hermes Trimegistro, afirmavam: o Todo está em todas as partes. Assim como é acima, é abaixo. O que afeta o mundo, afeta o indivíduo. E vice-versa.

Assim, penso que é nossa responsabilidade coletiva pensarmos o mundo, e buscarmos formas de reflexão e ação que possam resgatar o passado, cuidar do presente e preservar o futuro.

Estamos em momento de catástrofes climáticas, ecológicas, de biomas e de espécies biológicas, com tantos animais em perigo ou em processo de extinção. E há a urgentíssima catástrofe antropológica: continuamos a matar nossos semelhantes.

O Brasil, longe de ser um povo cordial, apresenta um dos maiores índices de violência do mundo. Peço licença para citar alguns números, que mostram a cruel realidade que vivemos e que de algum modo seguimos negando, reprimindo nossa consciência social, mantendo afastadas de nossa mente e de nossa capacidade de reação, o horror:

Segundo o "Atlas da Violência" (IPEA, 2021), o Brasil não sabe a causa de 17 mil mortes violentas do ano de 2019, sendo que os óbitos sem definição alcançam $12 \%$ do total de mortes por causas externas. Provavelmente trata-se de homicídios ocultos, pois quase 2.000 dessas mortes foram provocadas por armas de fogo. Dos mortos, há uma gritante desigualdade na composição étnica: os afrodescendentes são $76 \%$ das vítimas, e apresentam 2,6 mais chances de serem mortos. Mulheres pretas ou pardas tem $66 \%$ mais mortalidade do que brancas, indígenas ou amarelas.

Mas os povos originários e seus descendentes sofrem igual violência, pois segundo o mesmo relatório, a taxa de assassinatos de indígenas subiu $22 \%$ em uma década no país: foram 247 índios em 2017 e 186 em 2019. De acordo com a Comissão Pastoral da Terra (2020) aconteceram cinco conflitos por dia em 2019, com inúmeras invasões de terra, e um total de 32 assassinatos. São madeireiras e mineradoras devastando a Amazônia, o capitalismo selvagem e devorador. O CIMI (Conselho 
Indigenista Missionário) registrou 256 casos de invasões possessórias e danos ao patrimônio em pelo menos 151 terras indígenas, de 143 povos, em 23 estados aumento de $135 \%$ em relação a 2018.

O Brasil ostenta a triste estatística de ser um dos países em que acontecem mais mortes de mulheres e ataques físicos e emocionais a diversos membros da família, conformando um quadro de permanente violência doméstica. Os feminicídios foram 1338 em 2020, um homicídio a cada sete horas, e o número de estupros atinge uma proporção de um a cada oito minutos. Também os deficientes físicos e sensoriais sofrem, pois ainda segundo o IPEA (2021), o Brasil registrou ao menos 7.613 casos de violência contra pessoas com deficiência em 2019, o equivalente a quase um por hora.

Assim, aqui no Brasil e no restante do mundo, embora muito desigualmente distribuída, a violência continua ceifando ou mutilando vidas, e tornando os traumas psíquicos uma consequência inevitável dessa forma, tão pouco civilizada, do viver em sociedade.

Estamos matando, diariamente, imensamente: mortes por suicídio, por fome, por guerras (por território, económicas, religiosas, imperialistas ou etnocidas, incluindo o genocídio continuado dos povos originários), além de violência urbana, caos urbano, falta de condições sanitárias e saneamento básico (água e esgoto ainda faltam para 100 milhões de brasileiros e 2,1 bilhões de pessoas no mundo todo), expulsões e não aceitação de refugiados em todo o mundo (82 milhões de pessoas estão expatriadas), doenças de todo tipo, incluindo aquelas que só matam no Terceiro Mundo (evitáveis desde que houvesse estruturas de saúde adequadas), além de inúmeros outros fatores letais. O mundo está, inegavelmente, doente.

Mas, exatamente em função desse estado catastrófico, é possível antever que uma "mudança catastrófica", no sentido que Bion (1991) atribuía a essa expressão, já se aproxima e se prepara. A mudança catastrófica desequilibra todo o sistema e obriga-o a transformar-se. Está em gestação uma nova Era.

Há uma tarefa maravilhosa para as próximas gerações, mas que também é urgência de nossa atual geração, nós todos, coabitantes do planeta Terra em 2021 e para os muitos anos seguintes: - Ajudar a SONHAR um Novo Mundo. Ajudar a regenerar, a preparar, a ampliar e elaborar e "construir-recuperar" esse novo-antigo habitat em que devemos coexistir.

Ajudar a sonhar um novo mundo: impossível só se desistirmos, se nos entregarmos a esse suicídio admitido, essa morte anunciada, esse apocalipse por nós engendrado: um mundo que se afoga em sua autodestruição.

Roubamos sem parar da Terra, nós a esgotamos e a envenenamos. Nós a comemos, como afirma Davi Kopenawa, o sábio xamã yanomami, que nos alerta com extrema clareza:

Os brancos nos chamam de ignorantes apenas porque somos gente diferente deles. Na verdade, é o pensamento deles que se mostra curto e obscuro. Não consegue se expandir e se elevar, porque eles querem ignorar a morte.

Ficam sempre bebendo cachaça e cerveja, que lhes esquentam e esfumaçam o peito. É por isso que suas palavras ficam tão ruins e emaranhadas. Não queremos mais ouvi-las. 
Para nós, a política é outra coisa. São as palavras de Omama e dos xapiri que ele nos deixou. São as palavras que escutamos no tempo dos sonhos e que preferimos, pois são as nossas mesmo. Os brancos não sonham tão longe quanto nós. Dormem muito, mas só sonham consigo mesmos. (Kopenawa \& Albert, 2021, p. 37).

Assim, retomo aqui a sugestão/provocação/convocação que fiz anteriormente: precisamos convocar os jovens e todos os "homens e mulheres de boa vontade", a Sonhar e Realizar a construção de um planeta habitável, sustentável, de Natureza florescente e exuberante, com condições para todas as espécies vivas se perpetuarem, e sociedades humanas justas, saudáveis, integradas, não excludentes, não marginalizantes, não assassinantes.

Um sonho para todos. Homens e animais. Plantas e todos os componentes físicoquímicos do ambiente, todos conterrâneos, ou coterranos.

Outro brilhante intelectual brasileiro é também índio: chama-se Ailton Krenak, e também tem a generosidade de querer que não só eles, índios, sobrevivam, mas que todos nós, inclusive os brancos que os massacramos, possamos todos sobreviver. Diz Krenak:

Se enxergarmos que estamos passando por uma transformação, precisaremos admitir que nosso sonho coletivo de mundo e a inserção da humanidade na biosfera terão que se dar de outra maneira. Nós podemos habitar esse planeta, mas deverá ser de outro jeito. (Krenak, 2020, p. 44).

E esse lúcido intelectual cita um ancião da tribo Lakota, que dizia: "Quando o último peixe estiver nas águas e a última árvore for removida da terra, só então o homem perceberá que ele não é capaz de comer dinheiro" (Krenak, 2020, p. 13).

Estamos a tal ponto dopados por essa realidade nefasta de consumo e entretenimento que nos desconectamos do organismo vivo da Terra. Com todas as evidências, as geleiras derretendo, os oceanos cheios de lixo, as listas de espécies em extinção aumentando, será que a única maneira de mostrar para os negacionistas que a Terra é um organismo vivo é esquartejá-la? Picá-la em pedaços e mostrar: 'Olha, ela é viva'? É de uma estupidez absurda. (Krenak, 2020, p. 18).

Em seu extraordinário "Ideias para adiar o fim do mundo", Krenak questiona a ideia de humanidade, de uma forma que penso nunca antes ter sido apresentada. Nesse grande pequeno livro de apenas 102 páginas, o líder indígena questiona:

Como justificar que somos uma humanidade se mais de $70 \%$ estão totalmente alienados do mínimo exercício de ser? A modernização jogou essa gente do campo e da floresta para viver em favelas e em periferias, para virar mão de obra em centros urbanos. Essas pessoas foram arrancadas de seus coletivos, de seus lugares de origem, e jogadas nesse liquidificador chamado humanidade. Se as pessoas não tiverem vínculos profundos com sua memória ancestral, com as referências que dão sustentação a uma identidade, vão ficar loucas neste mundo maluco que compartilhamos. (Krenak, 2019, p. 14). 
Não é tarde demais. É muito importante salientar que, como relata esse sábio, "ainda existem aproximadamente 250 etnias que querem ser diferentes umas das outras no Brasil, que falam mais de 150 línguas e dialetos”. (Krenak, 2019, p. 31). Lembremos que cada língua é um universo. Cada um desses povos indígenas desenvolveu sua própria maneira de viver de maneira sustentável em seu mundo e ali criar e desenvolver um universo simbólico próprio.

Quero ainda ressaltar que as mulheres (o gênero feminino e a maneira feminina de sentir, pensar e agir) tem provavelmente o papel mais decisivo nessa busca por compreender a enorme crise em que estamos atolados, e fazer brotar (nascer!) daí novas possibilidades de superação desses incontáveis problemas contemporâneos. Inclusive as mulheres indígenas, como provam Sonia Guajajara, Nara Baré e as 85 organizações de mulheres indígenas no Brasil. Todos nós estamos envolvidos nessa luta pela vida.

$\mathrm{O}$ que isso tudo tem a ver com os Grupos, com a teoria e a prática da psicoterapia psicanalítica grupal, com a psicanálise dos vínculos, com os grupos operativos e as demais práticas grupais? Na minha opinião, tem tudo a ver. Melhor, tem tudo a pensar.

Precisamos repensar e ressignificar nossas práticas grupais. Precisamos, junto com as novas gerações, cuidar do presente e do futuro. Não podemos correr o risco de estarmos apenas buscando solucionar nosso complexo de Édipo enquanto o Céu pode desabar sobre nossas cabeças.

Somos profissionais psi que estudam e trabalham com os Vínculos. É preciso ampliarmos nossa visão e nossa atuação para podermos contribuir com a mais importante das redes vinculares: a Teia da Vida.

\section{REFERÊNCIAS}

Bion, W. R. (1991). O aprender com a experiência. Imago. Original publicado em 1961.

Comissão Pastoral da Terra (2020). Conflitos no campo: Brasil 2019. CPT Nacional. https://www.cptnacional.org.br/downlods?task=download.send\&id=14195\&catid= $0 \& m=0$

Instituto de Pesquisa Econômica Aplicada (IPEA) (2021). Atlas da Violência. https://www.ipea.gov.br/atlasviolencia/publicacoes

Jornal O Globo (2021, 12 de outubro). Gratificações e benefícios criam supersalários. https://oglobo.globo.com/economia/gratificacoes-beneficios-criam-supersalariosque-superam-teto-salarial-de-servidores-24687424

Kopenawa, D. \& Albert, B. (2021). A queda do céu. Palavras de um xamã yanomami. Cia das Letras.

Krenak, A. (2020). A vida não é útil. Cia das Letras.

Krenak, A. (2019). Ideias para adiar o fim do mundo. Cia das Letras.

Senado Notícias (2019, 25 de setembro). Brasil tem 48\% da população sem coleta de esgoto, diz Instituto Trata Brasil. https://www12.senado.leg.br/noticias/materias/2019/09/25/brasil-tem-48-dapopulacao-sem-coleta-de-esgoto-diz-instituto-trata-brasil.

Senado Notícias (2020, 13 de novembro). Dia Nacional da Alfabetização: senadores lamentam situação da educação durante a pandemia. 
https://www12.senado.leg.br/noticias/materias/2020/11/13/dia-nacional-daalfabetizacao-senadores-lamentam-situacao-da-educacao-durante-a-pandemia

UNICEF (2017, 13 de julho). 2,1 bilhões de pessoas não têm acesso a água potável em casa, e mais do dobro de pessoas não tem acesso a saneamento seguro. https://www.unicef.org/angola/comunicados-de-imprensa/21-bilh\%C3\%B5es-depessoas-n\%C3\%A3o-t\%C3\%AAm-acesso-\%C3\%A1 gua-pot\%C3\%A1vel-emcasa-e-mais-do-dobro

UOL (2021, 24 de junho). Desigualdade aumenta no Brasil, e 1\% da população $50 \%$ $d a$ riqueza. https://economia.uol.com.br/noticias/redacao/2021/06/24/distribuicao-riquezanacional---brasil.htm

Submetido: 23/10/2021

Reformulado: 10/11/2021

Aceito: $25 / 11 / 2021$

\section{Sobre o autor:}

Lazslo Antonio Ávila é professor adjunto, livre docente do Departamento de Psiquiatria e Psicologia Médica da Faculdade de Medicina de São José do Rio Preto (FAMERP). Membro do NESME e da SPAGESP.

Correspondência: lazslo@terra.com.br 